\title{
Effect of Applying Positive Pressure With or Without Endotracheal Suctioning During Extubation: A Laboratory Study
}

\author{
Mauro F Andreu PT, Iris G Salvati PT, Mariana C Donnianni PT, Belén Ibañez PT, \\ Mariana Cotignola PT, and Marco Bezzi PT
}

\begin{abstract}
BACKGROUND: During invasive mechanical ventilation, secretions accumulate in the subglottic space; consequently, there is a risk of aspiration of these secretions into the airway during cuff deflation and extubation. To minimize this risk, 2 extubation methods are used. The first consists of introducing a suction catheter into the endotracheal tube (ETT) and the trachea. After initiating suctioning, the cuff is deflated and the ETT is removed together with the suction catheter. The second technique involves applying positive pressure to the ETT using a resuscitation bag. Once the manual breath is delivered, the ETT cuff is deflated and the ETT is removed without suction. The aim of this laboratory study is to determine the existence and magnitude of differences in leak volume during cuff deflation and extubation using various combinations of positive pressure with or without endotracheal suctioning. METHODS: An ETT connected to a ventilator was placed in a model trachea. Colored water was instilled in the space above the cuff. To measure the leak volume, a collection chamber was attached to the distal end of the model. Nine procedures were defined, based on the delivery of different positive pressure levels with or without endotracheal suctioning during extubation. The volume of leakage, in milliliters, was the unit of analysis. Procedures yielding values lower than $1 \mathrm{~mL}$ were assessed by the Friedman test, and a $P$ value of less than .05 was considered significant. Post hoc comparisons were performed with a Wilcoxon test, followed by a Bonferroni correction. RESULTS: The application of CPAP ${ }_{15}$, pressure support ventilation (PSV) $15 / 10$, and $\mathrm{PSV}_{20 / 5}$ produced $0.4,0.2$, and $0.1 \mathrm{~mL}$ of leak volume, respectively. Statistically significant differences were found between $\mathrm{CPAP}_{15}$ and $\operatorname{PSV}_{15 / 10}(P=.003)$ and between $\mathrm{CPAP}_{15}$ and $\operatorname{PSV}_{20 / 5}(P=.01)$, but not between $\operatorname{PSV}_{15 / 10}$ and $\operatorname{PSV}_{20 / 5}(P=.30)$. The addition of suctioning increased leak volume, with statistically significant differences between $\mathrm{CPAP}_{15}$ and $\mathrm{CPAP}_{15}+$ endotracheal suctioning $(P=.001)$ and between $\operatorname{PSV}_{15 / 10}$ and $\operatorname{PSV}_{15 / 10}+$ endotracheal suctioning $(P=.001)$. CONCLUSIONS: Endotracheal suctioning during cuff deflation and extubation produced greater leakage. Application of $\mathrm{CPAP}_{15}, \mathrm{PSV}_{15 / 10}$, and $\mathrm{PSV}_{20 / 5}$ resulted in the lowest leak values, with the best results being obtained with the use of $\mathbf{P S V}_{\mathbf{1 5 / 1 0}}$ and $\mathbf{P S V}_{\mathbf{2 0 / 5}}$. Key words: airway extubation; endotracheal suctioning; extubation methods; positive pressure ventilation; aspiration; fluids leakage; positive end expiratory pressure. [Respir Care 2014;59(12):1905-1911. (C) 2014 Daedalus Enterprises]
\end{abstract}

Introduction

Discontinuation of invasive mechanical ventilation consists of 2 phases: weaning (abolishing the need for venti-

The authors are affiliated with the Intensive Care Unit, Diagnostic and Treatment Department, Hospital Santojanni, Buenos Aires, Argentina.

Mr Andreu presented this research at the First Bi-National ArgentineChilean Congress in Intensive Care, held September 22-25, 2013, in Mendoza, Argentina.

The authors have disclosed no conflicts of interest latory support) and extubation (removal of the endotracheal tube $[\mathrm{ETT}]$ when it is no longer required). ${ }^{1}$ Extubation is a commonly performed procedure in ICUs. However, this maneuver has received relatively little emphasis in the literature. ${ }^{2}$

Correspondence: Mauro F Andreu PT, Moldes 1528 Piso 3 Departamento A, C1426ALT, Buenos Aires, Argentina. E-mail: maufede@ hotmail.com.

DOI: $10.4187 /$ respcare. 03121 
During invasive mechanical ventilation, secretions accumulate in the subglottic space, above the ETT cuff. There is a risk that these oropharyngeal secretions will be aspirated into the airway during cuff deflation and extubation. ${ }^{3-5}$ Such aspiration of oropharyngeal content (leakage) may not have relevant clinical manifestations, although it could result in pneumonitis or pneumonia. ${ }^{4-6}$ Two extubation methods are mainly used, each intended to minimize this risk of leakage: extubation with a tracheal suction catheter and extubation with a resuscitation bag. ${ }^{2}$ The former is the traditional technique, which consists of introducing a suction catheter into the ETT and the trachea once oropharyngeal secretions have been cleared. After initiating suctioning, the cuff is deflated and the ETT is removed together with the suction catheter. ${ }^{7}$ However, the catheter may not be capable of suctioning all secretions, and, according to some authors, it may even facilitate leakage of these fluids into the distal airway. ${ }^{5,8}$ Negative pressure generated by the suction catheter may favor, rather than prevent or minimize, pulmonary aspiration. ${ }^{9}$ The second technique consists of extubation with positivepressure ventilation delivered by a resuscitation bag. ${ }^{2,7}$ It involves applying positive pressure to the ETT with $100 \%$ oxygen using a resuscitation bag. The ETT cuff is deflated and, once manual breaths are delivered, the ETT is removed without suction..$^{10}$ When secretions reach the oral cavity, they are cleared through a suction catheter. ${ }^{5}$ Although the suction catheter technique is the method traditionally used, a change in daily practice might reduce extubation-related complications. ${ }^{2,7}$

There is limited evidence in the literature as to the effect of different extubation methods on the leakage of material into the airway. In a laboratory study, a CPAP level of $35 \mathrm{~cm} \mathrm{H}_{2} \mathrm{O}$ during cuff deflation and extubation resulted in less aspiration when compared with the traditional method. 5 This recommended pressure level, however, may not be optimal for patients who are awake and ready for extubation. Therefore, we consider that other procedures that have not yet been studied, such as the use of pressure support (PS) and PEEP, may provide the same, if not more, benefit. Thus, the aim of this laboratory study is to determine the existence and magnitude of differences in leak volume during cuff deflation and extubation by using various combinations of positive pressure with or without endotracheal suctioning.

We hypothesize that applying positive pressure during cuff deflation and extubation reduces the likelihood of leakage of material placed above the ETT cuff.

\section{Methods}

From June 15 to December 15, 2012, a section of the ICU at Hospital General de Agudos Donación Francisco Santojanni (Buenos Aires, Argentina) was adapted to carry

\section{QUICK LOOK}

\section{Current knowledge}

During invasive mechanical ventilation, secretions accumulate in the subglottic space posing an aspiration risk during cuff deflation and extubation. To minimize this risk, both suctioning the endotracheal tube during tube removal and applying positive pressure with a manual resuscitator have been advocated.

\section{What this paper contributes to our knowledge}

In a laboratory study, endotracheal suctioning during cuff deflation and extubation resulted in increased leakage into the lower airway. The application of pressure support ventilation at $15 / 10 \mathrm{~cm} \mathrm{H}_{2} \mathrm{O}$ or $20 / 5 \mathrm{~cm} \mathrm{H}_{2} \mathrm{O}$ was associated with minimal leakage.

out this laboratory study. This study was approved by the institutional ethics committee.

The methodology for this study was adapted from a study by Hodd et al..$^{5}$ A polyvinylchloride trachea model (Plastirrabit, Buenos Aires, Argentina), $20 \mathrm{~cm}$ in length and $22 \mathrm{~mm}$ in internal diameter, was placed to simulate the Fowler's position. ${ }^{5}$ Because the trachea model was curved, inclination was obtained by drawing a straight line with a ruler from the proximal end to the distal end of the tube and orienting this line at an angle of $45^{\circ}$ from horizontal with the use of a gravity inclinometer.

The mean internal diameter of the adult male trachea has been reported to be $22 \mathrm{~mm} .{ }^{11}$ A water trap was positioned between the distal end of the trachea model and an Adult Test Lung 190 (Maquet, Wayne, New Jersey). To optimize measurement accuracy, the original water trap container was replaced with a plastic cylindrical-shaped container graduated in milliliters and occluded in its free end (Fig. 1).

The trachea model was intubated with an $8 \mathrm{~mm}$ internal diameter ETT (EMT Tracheal Tube Cuffed Murphy Eye, Mallinckrodt, Boulder, Colorado), which was replaced before initiating each extubation procedure. The choice of tube size was based on the fact that a size 8 tracheal tube is commonly used for endotracheal intubation of patients. ${ }^{8}$ The unlubricated cuff was placed $4.5 \mathrm{~cm}$ from the upper opening of the trachea model to simulate the normal airway anatomy. ${ }^{5}$ For each determination, before setting the ventilator, the ETT cuff was inflated with a manual manometer (cuff pressure gauge, VBM, Baden-Württemberg, Germany) until the pressure reached $60 \mathrm{~cm} \mathrm{H}_{2} \mathrm{O},{ }^{5,8}$ The use of this pressure level, significantly higher than what is recommended and commonly used in clinical practice, is justified by the fact that it prevents oropharyngeal contents from leaking past the cuff before cuff deflation and extu- 


\section{Positive Pressure and Suctioning During Extubation}

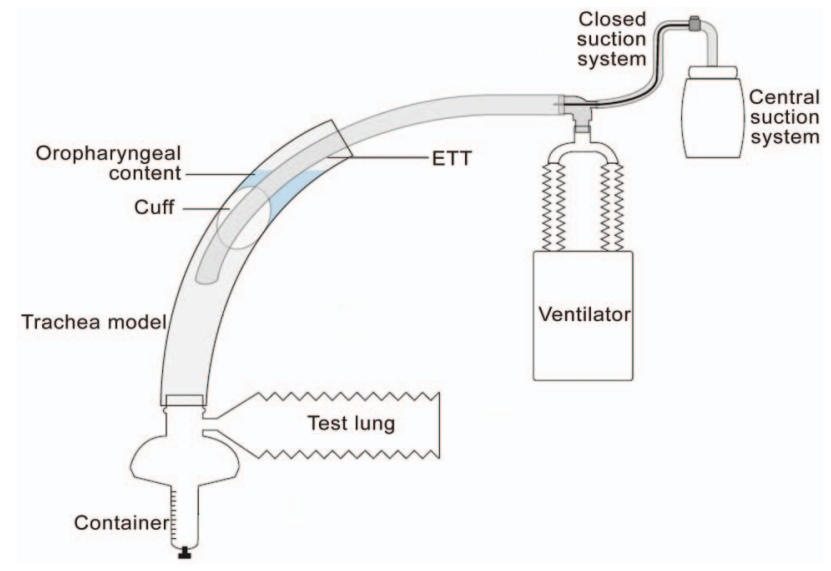

Fig. 1. Schematic illustration of the system. ETT = endotracheal tube.

bation and thus makes it possible to quantify leak volume exclusively associated with the procedure. ${ }^{5,8}$

Ten milliliters of methylene blue-colored water were poured through the subglottic port of the ETT. ${ }^{5}$ This fluid collection was referred to as oropharyngeal contents. The ETT proximal end was attached to a Maquet Servo-s ventilator. Nine procedures were defined using different levels of positive pressure with or without endotracheal suctioning during cuff deflation and extubation. CPAP and PS/ PEEP levels were adjusted as appropriate (Table 1). Due to the absence of inspiratory effort, while the system is closed (cuff inflated), the baseline pressure remains the same. Once the system is opened (upon cuff deflation), pressure drops and reaches the trigger threshold, thus initiating the inspiratory phase of the pressure support ventilation (PSV) mode. During CPAP mode, pressure drop generated once the system is opened results in a release of compensatory flow to maintain system pressurization at the programmed pressure.

The following ventilator parameters remained unchanged during the study: PSV mode, apnea time (45 s), trigger sensitivity $\left(-5 \mathrm{~cm} \mathrm{H}_{2} \mathrm{O}\right.$ ), and cycling criterion $(30 \%)$. The outcome measure was leak volume $(\mathrm{mL})$. A total of 15 measurements were recorded for each of the 9 procedures. A closed-envelope technique was used to randomly assign the order of procedure implementation. To minimize operator bias, the traditional method (procedure 7) was simulated without disconnecting the ventilator circuit and setting the CPAP at $0 \mathrm{~cm} \mathrm{H}_{2} \mathrm{O}$.

A $5.3 \mathrm{~mm}$ outer diameter closed suction system (Adult Trach Care, 16 French, Kimberly-Clark, Zaventem, Belgium) was attached between the ETT and the ventilator tubing. ${ }^{5}$ The wall suction system was calibrated by the hospital's biomedical engineering department to achieve a negative pressure level of $2 \mathrm{psi}(103 \mathrm{~mm} \mathrm{Hg})$, as recommended in the literature. ${ }^{12}$
Measurement procedure was performed by three operators as follows:

After randomization, the ventilator was set for the corresponding procedure by operator No. 1 . The proper timing for cuff deflation and extubation was indicated by this operator, who was the only person not blinded to the assigned protocol.

Immediately after the ventilator was set and ventilation initiated by operator No. 1, the maneuver was initiated by operator No. 2, who deflated the cuff with a $20 \mathrm{~mL}$ syringe and performed extubation. This operator could only see the proximal opening of the trachea model and the ETT because the rest of the system (trachea model, ventilator monitor, collection chamber, and test lung) was hidden behind a surgical drape.

Leak volume was measured and recorded by operator No. 3, who entered the site where the procedure was being performed only at the end of each extubation maneuver for data collection. Nonquantifiable remaining contents were expelled out (by the air flow resulting from cuff deflation) through the upper opening of the trachea model.

Before the study, the reliability of the procedure was determined by assessing inter- and intra-observer variability, assuming that a low variability implies the relevance of the process. A total of 15 measurements were taken by 2 operators with 2 and $10 \mathrm{y}$ of experience in the ICU. Inter-observer variability was assessed by coefficient of variation, with a value of less than 0.2 being considered satisfactory. Intra-observer variability was assessed by intraclass correlation coefficient.

\section{Statistical Analysis}

The cutoff point was $1 \mathrm{~mL}$ of oropharyngeal content leakage, with lower volumes being considered satisfactory. The volume of leakage $(\mathrm{mL})$, was the unit of analysis. Quantitative variables were expressed as median with interquartile range. Procedures yielding values lower than $1 \mathrm{~mL}$ were assessed by the Friedman test, and a $P$ value of less than .05 was considered significant. Post hoc comparisons were performed with a Wilcoxon test, followed by a Bonferroni correction. SPSS 17.0 software (SPSS, Chicago, Illinois) was used for this purpose.

\section{Results}

Coefficient of variation for the operators with 10 and $2 \mathrm{y}$ of experience in the ICU was 0.17 and 0.14 , respectively. The paired $t$ test revealed no significant differences (difference $=0.05,95 \% \mathrm{CI}-0.13$ to $0.24, P=.54$ ). Intraclass correlation coefficient was $0.46(P=.037)$. Median collected amounts for each of the 9 extubation procedures are described in Table 2. 
Table 1. Description of Procedures

\begin{tabular}{|c|c|c|}
\hline No. & Procedure & Description \\
\hline 1 & $\mathrm{CPAP}_{5}$ & $\begin{array}{l}\text { Ventilator parameters were set at a CPAP of } 5 \mathrm{~cm} \mathrm{H}_{2} \mathrm{O} \text {. Then, the cuff was deflated and } \\
\text { the ETT removed. }\end{array}$ \\
\hline 2 & $\mathrm{CPAP}_{10}$ & The same as in procedure 1 but applying a CPAP of $10 \mathrm{~cm} \mathrm{H}_{2} \mathrm{O}$. \\
\hline 3 & $\mathrm{CPAP}_{15}$ & The same as in procedure 1 but applying a CPAP of $15 \mathrm{~cm} \mathrm{H}_{2} \mathrm{O}$. \\
\hline 4 & $\mathrm{PSV}_{15 / 0}$ & $\begin{array}{l}\text { Ventilator parameters were set at a PS of } 15 \mathrm{~cm} \mathrm{H}_{2} \mathrm{O} \text { and a PEEP of } 0 \mathrm{~cm} \mathrm{H}_{2} \mathrm{O} \text {. Then, the } \\
\text { cuff was deflated and the ETT removed. }\end{array}$ \\
\hline 5 & $\mathrm{PSV}_{15 / 10}$ & The same as in procedure 4 but applying a PS of $15 \mathrm{~cm} \mathrm{H}_{2} \mathrm{O}$ and a PEEP of $10 \mathrm{~cm} \mathrm{H}_{2} \mathrm{O}$. \\
\hline 6 & $\mathrm{PSV}_{20 / 5}$ & The same as in procedure 4 but applying a PS of $20 \mathrm{~cm} \mathrm{H}_{2} \mathrm{O}$ and a PEEP of $5 \mathrm{~cm} \mathrm{H}_{2} \mathrm{O}$. \\
\hline 7 & Traditional & $\begin{array}{l}\text { Ventilator parameters were set at a CPAP of } 0 \mathrm{~cm} \mathrm{H}_{2} \mathrm{O} \text {. The catheter of the closed suction } \\
\text { system was introduced } 2 \mathrm{~cm} \text { below the distal end of the ETT. Endotracheal suctioning } \\
\text { was initiated, and, without discontinuing it, the cuff was deflated and the ETT removed. }\end{array}$ \\
\hline 8 & $\mathrm{CPAP}_{15}+$ endotracheal suctioning & The same as in procedure 7 but applying a CPAP of $15 \mathrm{~cm} \mathrm{H}_{2} \mathrm{O}$. \\
\hline 9 & $\mathrm{PSV}_{15 / 10}+$ endotracheal suctioning & The same as in procedure 7 but applying a PS of $15 \mathrm{~cm} \mathrm{H}_{2} \mathrm{O}$ and a PEEP of $10 \mathrm{~cm} \mathrm{H}_{2} \mathrm{O}$. \\
\hline
\end{tabular}

$\overline{\mathrm{ETT}}=$ endotracheal tube

PSV $=$ pressure support ventilation

PS $=$ pressure support

Table 2. Comparison of Procedures Yielding Leak Values

\begin{tabular}{llr}
\hline \hline No. & Procedure & $\begin{array}{c}\text { Leak } \\
\text { Volume } \\
(\mathrm{mL})\end{array}$ \\
\hline 1 & $\mathrm{CPAP}_{5}$ & $5.2(4.3-5.6)$ \\
2 & $\mathrm{CPAP}_{10}$ & $1.9(1.4-2.2)$ \\
3 & $\mathrm{CPAP}_{15} *$ & $0.4(0.3-0.7)$ \\
4 & $\mathrm{PSV}_{15 / 0}$ & $9.1(8.7-9.4)$ \\
5 & $\mathrm{PSV}_{15 / 10} *$ & $0.2(0.1-0.3)$ \\
6 & $\mathrm{PSV}_{20 / 5} *$ & $0.1(0.0-0.2)$ \\
7 & $\operatorname{Traditional~}_{8}$ & $9.4(9.1-9.6)$ \\
8 & $\mathrm{CPAP}_{15}+$ endotracheal suctioning & $7.9(7.7-8.1)$ \\
9 & $\mathrm{PSV}_{15 / 10}+$ endotracheal suctioning & $4.2(4.0-5.0)$ \\
& & \\
\hline $\begin{array}{l}\text { Procedures yielding leak values }<1 \text { mL were compared: procedure } 3 \text { vs procedure } 5 . \\
(P=.003) ; \text { procedure } 3 \text { vs procedure } 6(P=0.01) \text { procedure } 5 \text { vs procedure } 6(P=.30) . \text { Data }\end{array}$ \\
are shown as median with interquartile range in parentheses. \\
* Procedures yielding leak values $<1$ ml. \\
\hline
\end{tabular}

The traditional procedure produced the greatest amount of oropharyngeal content leakage $(9.4 \mathrm{~mL})$, a value that is far higher than the one arbitrarily defined as an acceptable difference for this study. Low levels of positive pressure $\left(\mathrm{CPAP}_{5}, \mathrm{CPAP}_{10}\right.$, and $\left.\mathrm{PSV}_{15 / 0}\right)$ yielded leak values of 5.2, 1.9, and 9.1, respectively. The lowest leak levels were obtained with $\mathrm{CPAP}_{15}, \mathrm{PSV}_{15 / 10}$, and $\mathrm{PSV}_{20 / 5}(0.4,0.2$, and 0.1 , respectively) (Table 2 and Fig. 2). Because the leak volume was lower than the preset value during these procedures, a Friedman test was performed to determine whether there was a significant difference among them. Differences were statistically significant $(P=.003)$.

We performed a post hoc paired comparison test, setting the level of significance at a $P$ value of less than .02 after Bonferroni correction: $\mathrm{p} / 0.5 \mathrm{k} \times(\mathrm{k}-1)$. Statistically sig- nificant differences were found between $\mathrm{CPAP}_{15}$ and $\operatorname{PSV}_{15 / 10}(P=.003)$, and between $\mathrm{CPAP}_{15}$ and $\mathrm{PSV}_{20 / 5}$ $(P=.01)$, but not between $\operatorname{PSV}_{15 / 10}$ and $\operatorname{PSV}_{20 / 5}(P=.30)$ (Table 2).

During procedures with positive pressure, the addition of suctioning resulted in increased leak volume, with statistically significant differences between $\mathrm{CPAP}_{15}$ and $\mathrm{CPAP}_{15}+$ endotracheal suctioning $(P=.001)$, and between $\mathrm{PSV}_{15 / 10}$ and $\mathrm{PSV}_{15 / 10}+$ endotracheal suctioning $(P=.001)$ (Table 3$)$.

\section{Discussion}

In this study, any maneuver capable of maintaining system pressurization reduced the leakage of oropharyngeal contents pooled above the ETT cuff. One of the findings in this study was an inverse trend between the amount of leakage and the level of positive pressure applied during extubation with CPAP. This confirms what was reported in the study conducted by Hodd et al, ${ }^{5}$ where only 1.6 out of $10 \mathrm{~mL}$ of oropharyngeal contents were aspirated when applying $35 \mathrm{~cm} \mathrm{H}_{2} \mathrm{O}$ of CPAP.

There are no available data in the literature as to the clinical importance of aspirated oropharyngeal contents. We have arbitrarily defined as acceptable a difference in leak volume of less than $1 \mathrm{~mL}$ as compared with $3 \mathrm{~mL}$ in the study by Hodd and co-workers. ${ }^{5}$ This is justified on the grounds that, in a pilot study, with lower values of CPAP, we collected lower leak volumes than those reported by these authors. Differences found may be due to the fact that they have used a threshold resistor device (spring-loaded PEEP valve). This valve generates a positive pressure level; however, once the system is opened (upon cuff deflation), this pressure drops 


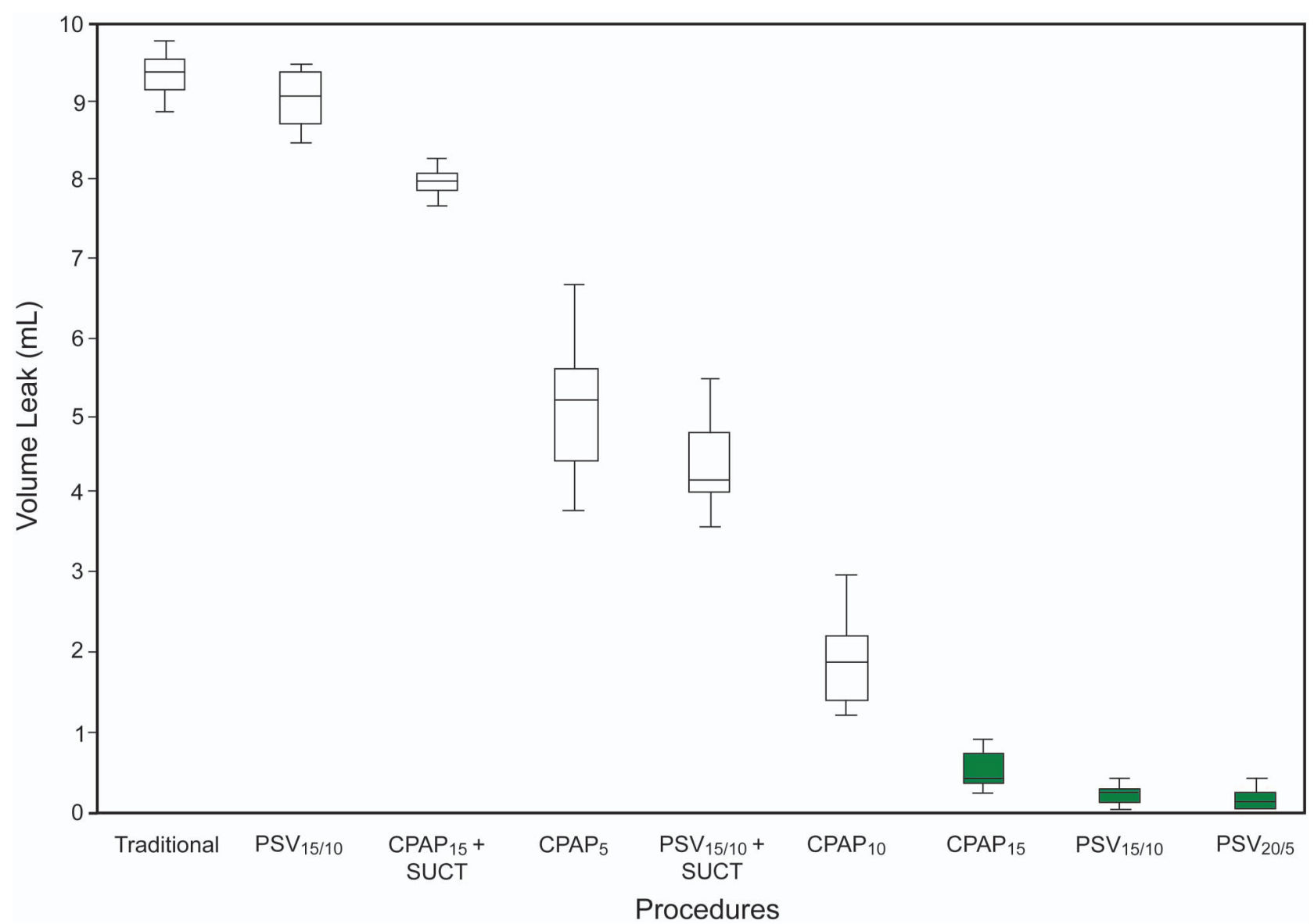

Fig. 2. Box plot for each procedure. For each data box, the horizontal line represents the median, the bottom and top represent the 25th and 75th percentiles, and the whisker bars represent the minimum and maximum values. Procedures yielding values $<1 \mathrm{~mL}$ are highlighted in green. PSV = pressure support ventilation; SUCT = suctioning (see Table 1 for procedure descriptions).

Table 3. Comparison Among Procedures With and Without Endotracheal Suctioning

\begin{tabular}{lccc}
\hline \hline Procedure & $\begin{array}{c}\text { Without } \\
\text { Endotracheal } \\
\text { Suctioning }\end{array}$ & $\begin{array}{c}\text { With } \\
\text { Endotracheal } \\
\text { Suctioning }\end{array}$ & $P$ \\
\hline $\mathrm{CPAP}_{15}$ & $0.4(0.3-0.7)$ & $7.9(7.7-8.1)$ & .001 \\
$\mathrm{PSV}_{15 / 10}$ & $0.2(0.1-0.3)$ & $4.2(4.0-5.0)$ & .001 \\
\hline Data are shown as median with interquartile range. & & \\
\hline
\end{tabular}

and tends to be equal to atmospheric pressure. In contrast, with the use of a ventilator during PSV mode, any pressure drop resulting from cuff deflation is detected by the device, which triggers the inspiratory phase by injecting additional air flow to raise the programmed pressure support level. During CPAP mode, pressure drop is compensated by injecting the flow needed to maintain the programmed pressure.

Air leakage around the ETT reduces leakage of oropharyngeal contents. A high level of CPAP for extubation may not be applicable in daily practice due to the potential discomfort and the risk of complications reported in the literature. ${ }^{13,14}$

Another finding of this study was the presence of leakage values of less than $1 \mathrm{~mL}$ during procedures with $\mathrm{CPAP}_{15}, \mathrm{PSV}_{15 / 10}$, and PSV $\mathrm{P}_{20 / 5}$. However, PS/PEEP combinations would be more clinically appropriate alternatives for patients who are able to tolerate the removal of the artificial airway, as they allow the patient to breathe at 2 different levels of pressure more comfortably and safely.

When using $\mathrm{PSV}_{15 / 0}$, results differed from those obtained with the use of $\mathrm{CPAP}_{15}$. Cuff deflation during $\mathrm{PSV}_{15 / 0}$ resulted in the immediate leakage of almost all oropharyngeal contents. A possible reason could be the lack of pressurization of the circuit before cuff deflation, which does not counteract leakage of oropharyngeal contents.

As mentioned above, one of the objectives of endotracheal suctioning during extubation is to minimize leakage of the oropharyngeal contents. ${ }^{5}$ However, we have found that endotracheal suctioning resulted in greater leakage. 


\section{Positive Pressure and Suctioning During Extubation}

This may be attributed to the fact that the degree of negative pressure generated by suctioning counteracts the pressure gradient between the system and the atmospheric pressure, which would otherwise tend to propel secretions outward. Therefore, with the traditional method, where no prior pressurization exists, we found the greatest amount of leakage. The disadvantageous effect of suctioning was also evident in those procedures where no leakage had been observed $\left(\mathrm{CPAP}_{15}\right.$ and $\left.\mathrm{PSV}_{15 / 10}\right)$. Consequently, suctioning should not be used during extubation because it favors aspiration of oropharyngeal contents, rather than preventing or minimizing it. It should be noted that, according to a survey of respiratory therapists and physicians in the city and the province of Buenos Aires, the traditional extubation technique is the most commonly used extubation method in daily practice (unpublished data).

Similar results were obtained in a survey of 179 ICUs in the United Kingdom, where 85\% reported performing the extubation technique with a suction catheter, whereas only $15 \%$ reported carrying out extubation with positivepressure ventilation. ${ }^{3}$

The protective cough mechanism would expel the aspirated oropharyngeal contents out during cuff deflation. However, residual effects of sedoanalgesia may reduce or suppress the cough reflex, and periglottic sensation may be abnormal for up to $8 \mathrm{~h}$ following extubation. ${ }^{15}$ Burgess and colleagues ${ }^{16}$ reported pulmonary aspiration in 8 of 24 patients who swallowed a solution immediately after extubation. Surprisingly, none of them coughed during the test.

There are other techniques to minimize the presence/aspiration of oropharyngeal contents. Oropharyngeal secretions can be suctioned through the mouth via a suction catheter. However, oral suctioning does not afford access to fluids that have accumulated between the endotracheal cuff and the vocal cords. Furthermore, it may stimulate the gag reflex, thereby increasing the risk for gastroesophageal reflux. Another mechanism aimed at reducing the amount of oropharyngeal contents is the use of endotracheal tubes with subglottic suction ports. However, its benefits are controversial. Limitations include: frequent obstruction, potential for tracheal mucosal damage, and risk of laryngeal edema and vocal cord injury due to the rigidity and greater outer diameter of the subglottic suction ETT. ${ }^{17}$

We did not assess oropharyngeal contents of different viscosities. We used a fluid viscosity with the goal of increasing the possibility of leakage during procedures. With the use of oropharyngeal contents that exhibit higher viscosities, our results would assuredly have been different.

Findings from this laboratory study invite one to question the role of endotracheal suctioning during cuff deflation and extubation. Although the clinical impact of oropharyngeal content leakage during extubation is unknown, practitioners could consider using the proposed techniques $\left(\mathrm{PSV}_{15 / 10}\right.$ and $\left.\mathrm{PSV}_{20 / 5}\right)$ on a routine basis. The stage is thus set for future studies to examine the clinical applicability of these techniques during cuff deflation and extubation.

\section{Conclusions}

Findings from this laboratory study allow us to conclude that the use of endotracheal suctioning during cuff deflation and extubation resulted in increased leakage. When applying $\mathrm{CPAP}_{15}, \mathrm{PSV}_{15 / 10}$, and $\mathrm{PSV}_{20 / 5}$, leakage values were lower than $1 \mathrm{~mL}$ (study cutoff point); however, the best results were obtained with the use of $\mathrm{PSV}_{15 / 10}$ and $\mathrm{PSV}_{20 / 5}$.

\section{ACKNOWLEDGMENTS}

We thank the following persons for their contributions to this study: Gabriela Montes PT, Carla Aguirre PT, Analía Occhiuzzi PT, Paula Pedace PT, Florencia Esmoris PT, Mariana Fredes PT, Sebastián Martinez PT, Mónica Gallelli PT, Elizabeth Múzio PT, Norberto Tiribelli PT, Andrés Leoz PT, Mariana Aguirre PT, Silvina Borello PT, Martín Miles PT, and Mario Rípoli MD.

\section{REFERENCES}

1. Epstein SK. Extubation failure: an outcome to be avoided. Critical Care 2004;8(5):310-312.

2. Suresh NS, Cheesman M. A survey of the current practice of tracheal extubation in intensive care units in England and Wales: trailing suction catheter technique vs. positive pressure breath technique. Anaesthesia 2006;61(1):92-93

3. Hodd J, Doyle A, Carter J, Albarran J, Young P. Extubation in intensive care units in the UK: an online survey. Nurs Crit Care 2010;15(6):281-284

4. Estes RJ, Meduri GU. The pathogenesis of ventilator associated pneumonia: 1. Mechanisms of bacterial transcolonization and airway inoculation. Intensive Care Medicine 1995;21(4):365-383.

5. Hodd J, Doyle A, Carter J, Albarran J, Young P. Increasing positive end expiratory pressure at extubation reduces subglottic secretion aspiration in a bench-top model. Nurs Crit Care 2010;15(5):257-261.

6. Safdar N, Crnich CJ, Maki DG. The pathogenesis of ventilatorassociated pneumonia: its relevance to developing effective strategies for prevention. Respir Care 2005;50(6):725-739; discussion 739741.

7. Scales K, Pilsworth J. A practical guide to extubation. Nurs Stand 2007;22(2):44-48.

8. Young PJ, Rollinson M, Downward G, Henderson S. Leakage of fluid past the tracheal tube cuff in a benchtop model. Br J Anaesth 1997;78(5):557-562.

9. Dave MH, Frotzler A, Madjpour C, et al. Massive aspiration past the tracheal tube cuff caused by closed suction system. J Intensive Care Med 2011;26(5):326-329.

10. Guglielminotti J, Constant I, Murat I. Evaluation of routine tracheal extubation in children: inflating or suctioning technique? $\mathrm{Br} \mathrm{J}$ Anaesth 1998;81(5):692-695.

11. Mehta S, Myat HM. The cross-sectional shape and circumference of the human trachea. Ann R Coll Surg Engl 1984;66(5):356358. 


\section{Positive Pressure and Suctioning During Extubation}

12. Pedersen CM, Rosendahl-Nielsen M, Hjermind J, Egerod I. Endotracheal suctioning of the adult intubated patient: what is the evidence? Intensive Crit Care Nurs 2009;25(1):21-30.

13. Luecke T, Pelosi P. Clinical review: positive end-expiratory pressure and cardiac output. Critical Care 2005;9(6):607-621.

14. Gil Cano A, Monge García MI, Gracia Romero M, Díaz Monrové JC. Incidencia, características y evolución del barotrauma durante la ventilación mecanica con apertura pulmonar. Med Intensiva 2012; 36(5):335-342.
15. Sharar S. Weaning and extubation are not the same. Respir Care 1995;40(3):239-243.

16. Burgess GE 3rd, Cooper JR Jr, Marino RJ, Peuler MJ, Warriner RA 3rd. Laryngeal competence after tracheal extubation. Anesthesiology 1979;51(1):73-77.

17. Gentile MA, Siobal MS. Are specialized endotracheal tubes and heat-and-moisture exchangers cost-effective in preventing ventilator associated pneumonia? Respir Care 2010;55(2):184-196; discussion 196-197. 